\title{
Lightning Protection for the Orion Space Vehicle
}

\author{
Robert Scully ${ }^{1}$ \\ NASA Johnson Space Center, Houston, Texas, 77058-3696
}

\begin{abstract}
The Orion space vehicle is designed to requirements for both direct attachment and indirect effects of lightning. Both sets of requirements are based on a full threat $200 \mathrm{kA}$ strike, in accordance with constraints and guidelines contained in SAE ARP documents applicable to both commercial and military aircraft and space vehicles. This paper describes the requriements as levied against the vehicle, as well as the means whereby the design shows full compliance.
\end{abstract}

\section{Nomenclature}

(this section TBD)

A $\quad=$ amplitude of oscillation

\section{Introduction}

$\mathrm{T}$ The Orion space vehicle is designed to requirements for both direct attachment and indirect effects of lightning. Both sets of requirements are based on a full threat 200kA strike, in accordance with constraints and guidelines contained in SAE ARP documents applicable to both commercial and military aircraft and space vehicles. These requirements were levied upon the vehicle to provide for full protection during ground processing, pad stay, ascent, descent, and recovery. Additional benefit from this approach results in a very robust electromagnetic compatibility design, providing assurance the vehicle will perfrom its intended missions without regard to environmental threats from external continuous wave or impulsive radio frequency sources, or triboelectricfication during ascent.

The goal of the design for direct attachment was to ensure the vehicle would survive such an event without loss of integrity, protecting the crew from harm and enabling continuance of flight to orbit, or descent to safe landing under abort or normal descent operations. The goal of the design for indirect effects was to ensure continued and safe operation of all systems, without damage to critical systems, although upset, with recovery both with and without operator intervention, during a strike event was allowed.

Basic requirements were taken from the SAE ARP 54XX series of lightning standards, and then tailored as appropriate to the vehicle. The vehicle was zoned, and with this accomplished, the various levels expected to appear on internal surfaces and cables, and ultimately pins of electrical and avioinic equipment, were determined through analysis using detailed knowledge of the vehicle structural design including the composite materials employed, the manner of electrical bonding of both external and internal components, shielding characteristics of the various structural materials, cable shields, and electrical equipment enclosures.

Testing using a swept continuous wave injection to the vehicle will be performed during certification of the vehicle to demonstrate the design satisfies all indirect effects requirements. Cables and pins will be selected for instrumentation during the testing tomonitor the cable responses to the presence of the swept signals, allowing for extrapolation of the results to a full threat event, regardless of waveshape. Data from this testing will also be available for future analysis, should minor design changes occur, allowing for determination of compliance without the need for additional testing. Testing of representative coupons is planned to demonstrate that structural elements satisfy the direct effecs requirements. Such testing would need to be reperformed if structural elements are altered, or different materials are employed in the construction of the vehicle.

1 Johnson Space Center Lead EMC Engineer, Avionic Systems Division, 2101 NASA Road 1, BIdg 14, Rm 122/EV511. Author is not an AIAA member. 